\title{
A EDUCAÇÃO BRASILEIRA NO MÊS DE ABRIL
}

\author{
1 - ATOS DA ADMINISTRAÇão FEDERAL
}

3 - E' publicada a ata de 24-3-44. do Conselho Nacional de Educação, relativa à 4.* sessão da 1.* reunião ordinária do ano.

S - É publicado o Decreto número 15.136, de 24-3-44, que autoriza o Ginásio Normal Marista, com sede em Recife, Estado de Pernambuco, a funcionar como colégio.

5 - É publicado o Decreto número 15.175, de 29-3-44, que concede reconhecimento, sob regime de inspeção permanente, ao curso ginasial do Ginásio Marcelino Champagnat, com sede em Curitiba, Estado do Paraná.

5 - É publicado o Decreto número 15.179, de 29-3-44, que concede reconhecimento, sob regime de inspeção permanente, ao curso ginasial do Ginásio N. S. das Lágrimas, com sede em Uberlândia, Estado de Minas Gerais.

6 - É publicado o Decreto número 15.173 , de 29-3-44. que autoriza o Ginásio Municipal de Castelo, com sede em Castelo, Estado do Espírito Santo, a funcionar como colégio.

6 - É publicada a portaria número 128 , de 7-3-44, do Ministro da Educação, que suspende, definitivamente, a pedido, a inspeção concedida à Escola Técnica de Comércio Dom
Bosco, com sede em Campo Grande, Estado de Mato Grosso.

8 - É publicado o Decreto-lei número 6.404, de 5-4-44, que revigora, no corrente ano, para os estabelecimentos de ensino superior subordinados ao Ministério da Agricultura,'as disposições do Decreto-lei n. ${ }^{\circ} 3.143$, de 25-341 , que permite a realização de novas provas dos concursos de habilitação ou exames vestibulares.

8 - É publicado o Decreto número 14.963 de 7-3-44, que autoriza o Ginásio Cardeal Leme, com sede no Distrito Federal, a funcionar como colégio.

10 - É publicado o Decreto número 15.275 , de 4-4-44, que concede reconheci mento, sob regime de inspeção perma nente, ao curso ginasial do Ginásio Dio cesano Santa Cruz, com sede em Castro, Estado do Paraná.

11 - É publicado o Decreto número 15.276, de 4-4-44, que autoriza o Ginásio Guido de Fontgalland, com sede em Maceió, Estado de Alagoas, a funcionar como colégio.

11 - É publicada a portaria número 93, de 6-4-44, do Ministro da Aeronáutica, que fixa em 16 o número de vagas à matrícula, no corrente ano, no Curso-Especial de Saúde. 
11 - É publicado o aviso $n .^{\circ} 848$, de 8-4-44, do Ministro da Guerra, que manda organizar cursos regionais de graduados na 4. ${ }^{a}$ Região Militar, nos moldes estabelecidos pelo aviso número 2.201, de 28-8-42.

12 - É publicado o Decreto número 15.165, de 29-3-44, que concede reconhecimento, sob regime de inspeção permanente, ao curso ginasial do Ginásio Batista Fluminense, com sede em Campos, Estado do Rio de Janeiro.

12- É publicado o Decreto número 15.185 , de 29-3-44, que concede equipa ração, sob regime de inspeção perma nente, ao curso ginasial do Ginásio do Estada, com sede em Presidente Prudente, Estado de São Paulo.

13 - É publicado o Decreto nú mero 15.336, de 11-4-44, que modifica o art. 66 do Regulamento da Escola Nacional de Engenharia.

13 - É publicada a ata de $27-3-44$, do Conselho Nacional de Educação, relativa à $5 .^{\mathrm{a}}$ sessão da $1 .^{\mathrm{a}}$ reunião ordinária do ano.

14 - É publicada a portaria nú mero 686, de 12-4-44, do Presidente do Departamento Administrativo do Ser viço Público, que cria, nos Cursos de Administração da Divisão de Aperfei çoamento, um curso extraordinário de Língua Portuguesa, destinado aos bol sistas estrangeiros em missão de es tudos no Brasil.

15- É publicado o Decreto número 14.957, de 7-3-44, que autoriza o Ginásio da Escola Normal Conselheiro Rodrigues Alves, como sede em Guaratin-guetá, Estado de São Paulo, a funcionar como colégio.

15 - É publicado o Decreto número 15.037, de 14-3-44, que autoriza o Giná- sio de Ciências e Letras, com sede na capital do Estado de São Paulo, a funcionar como colégio.

15 - É publicado o Decreto número 15.182, de 29-3-44, que concede equiparação, sob regime de inspeção permanente, ao curso ginasial do Ginásio do Estado, com sede em Bauru, Estado de São Paulo.

17 - É publicado o aviso n. ${ }^{\circ} 885$, de 14-4-44, do Ministro da Guerra, que autoriza o funcionamento, no corrente ano, de uma turma do curso normal da Escola de Moto-Mecanização para 26 oficiais-tenentes e capitães.

17 - É publicado o aviso n. ${ }^{\circ} 887$, de 14-4-44, do Ministro da Guerra, que suspende as matrículas em C.P.O.R. e N.P.O.R., no corrente ano.

18 - É publicada a portaria $\mathrm{n}^{\circ} 181$, de 29-3-44, do Ministro da Educação, que suspende, a pedido, a fiscalização prévia concedida à Escola Comercial do Ateneu São Luís, com sede no Distrito Federal.

19 - É publicada a portaria $\mathrm{n} .^{\circ} 201$, de 19-4-44, do Ministro da Educação, que expede instruções para regularização da vida escolar de alunos nos termos dos Decreto-leis n. ${ }^{\circ} \mathrm{s} \quad 5.545$, de 4-6-43, e 6.273, de 14-2-44.

19 - É publicada a portaria $\mathrm{n} .^{\circ} 202$, de 19-4-44, do Ministro da Educação, que estende aos alunos dos estabelecimentos de ensino superior, que ainda estejam funcionando sem reconhecimento oficial, os favores estabelecidos pelos Decretosleis n. ${ }^{\circ}$ s 5.545 , de 4-6-43, e 6.273 , de $14-$ 2-44, e pela portaria ministerial n. ${ }^{\circ} 201$.

20 - É publicado o aviso n. ${ }^{\circ} 34$, de 11 4-44, do Ministro da Aeronáutica, que fixa a distribuição dos alunos da 7." turma do Curso de Especialistas, 
cuja promoção ao $2 .^{\circ}$ período deverá ser efetuada a 1 de maio do corrente ano.

24 - É publicado o Decreto número 15.176, de 29-3-44, que concede reco nhecimento, sob regime de inspeção per manente, ao curso ginasial do Ginásio Divina Providência, com sede em Curi tiba. Estado do Paraná.

24 - É publicado o Decreto número 15.177, de 29-3-44, que concede equipa ração, sob regime de inspeção perma nente, ao curso ginasial do Ginásio $\mathrm{Pa}$ ranaense, seção feminina, com sede em Curitiba, Estado do Paraná.

24 - É publicado o Decreto número 15.155, de 27-3-44, que autoriza o Ginásio Iguaçu, cont sede em Curitiba. Estado do Paraná, a funcionar como colégio.

24 - É publicado o Decreto número 15.278, de 4-4-44, que concede reconhecimento ao curso ginasial do Ginásio $\mathrm{N}$. S. Auxiliadora, com sede em Batatais, Estado de São Paulo.

24 - É publicada a portaria número 696, de 19-4-44, do Presidente do Departamento Administrativo do Serviço Público, que cria, nos Cursos de Administração da Divisão de Aperfeiçoamento, um Curso de Preparação de Taquígrafos, e aprova as instruções para o seu funcionamento.

$24-\hat{E}$ publicada a portaria n. ${ }^{\circ} 207$, de 2Ü-4-44, do Ministro da Educação, que dispõe sobre os VI Jogos Universitários Brasileiros.

24 - É publicada a ata de 31-3-44, do Conselho Nacional de Educação. relativa à $7 .^{\mathrm{a}}$ sessão da $1 .^{\mathrm{a}}$ reunião ordinária do ano.

24 - É publicada a portaria n. ${ }^{\circ} 18$, de 19-4-44, do Ministro do Trabalho, que institui concurso para a escolha de uma cartilha para a alfabetização de operários adultos.

24 - É publicada a portaria n. ${ }^{\circ} 19$, de 19-4-44, do Ministro do Trabalho, que abre inscrição para " professor voluntário" do Serviço de Recreação Operária.

25 - É publicado o Decreto número 15.162, de 29-3-44, que conceda reconhecimento, sob regime de inspeção permanente, ao' curso ginasial do Ginásio Juvenal de Carvalho, com sede em Fortaleza, Estado do Ceará.

25 - É publicado o Decreto número 15.180, de 29-3-44, que concede reconhecimento, sob regime de inspeção permanente, ao curso ginasial do Ginásio Pio XI, com sede em Manhumirim, Estado de Minas Gerais.

26 - É publicado o aviso n. ${ }^{\circ}$ 966, de $24-$ 4-44, do Ministro da Guerra, que declara que os sargentos das F.S.R. possuidores do C.C.S. de fileira (partes comum e complementares), poderão concorrer à matrícula nos C.R.A.S., ainda no corrente ano.

28 - É publicado o Decreto número 14.957, de 7-3-44, "que autoriza o Ginásio Rui Barbosa, com sede em Jacarezinho, Estado do Paraná, a funcionar como colégio.

28 - É publicado o Decreto número 14.964, de 7-3-44, que autoriza o Ginásio José Bonifácio, com sede em Paranaguá, Estado do Paraná, a funcionar como colégio.

28 - É publicada a portaria n. ${ }^{\circ} 704$, de 26-4-44, do Presidente do Departamento Administrativo do Serviço Público, que aprova a proposta do programa de treinamento de funcionários em 1944, apresentada pela Divisão de Aperfeiçoamento. 
28 - É publicada a portaria n. ${ }^{\circ} 4$, de $18-4$ 44, do diretor do Conservatório Nacional de Canto Orfeônico, que dispõe sobre cursos de formação de professores especializados em canto orfeônico.

29 - É publicado o aviso de 24-4-44, do Ministro da Educação, que declara que a ortografia em vigor no país é rigorosamente a que decorre do acordo firmado em 1931 entre a Academia Brasileira de Letras e a Academia das Ciências de Lisboa.

\section{II - ATOS DA ADMINISTRAÇÃO DOS ESTADOS E DO DISTRITO FEDERAL}

1 - É publicado o Decreto do Estado do Amazonas, que mantém, durante o ano letivo, 24 escolas de emergência no município de Manaca-puru.

1 - É publicado o ato n. ${ }^{\circ}$ 541, de 31-3-44, do Estado de Pernambuco, que designa os professores Antônio Vítor de Araújo, Salvador Nigro e Elpídio Domingues Lins, para membros do Conselho Técnico do Curso de Agronomia da Escola Superior de Agricultura de Pernambuco.

1 - É publicado o Decreto do Estado do Paraná, que declara de utilidade pública um terreno destinado à construção do Colégio Estadual do

Paraná.

1 - É publicado o Decreto n. ${ }^{\circ} 1.005$, de 31-3-44, do Estado do Rio Grande do Sul, que cria um grupo escolar de $1^{\circ}$ estágio em São Jorge, município de São Francisco de Paula.

1 - É publicado o Decreto n. ${ }^{\circ} 1.007$, de 31-3-44, do Estado do Rio Grande do Sul, que dá nova redação ao art. $1 .^{\circ}$ do Decreto n. ${ }^{\circ} 977$, de 8-3-44, que criou uma escola isolada de $1 .^{\circ}$ estágio junto ao $3 .^{\circ}$ Batalhão Ferroviário, sediado em Lagoa Vermelha.

2 - É publicado o Decreto-lei nú mero 973, de 1-4-44, do Estado de Pernambuco, que doa à Escola de Belas Artes o prédio n. ${ }^{\circ} 150$ da rua Benfica, em Recife.

3 - É publicado o decreto do governo do Estado do Amazonas, que muda a denominação do grupo escolar "Eduardo Ribeiro" da capital para "Professora Libánia Ferreira".

3 - É publicado o decreto do Es tado do Amazonas que mantém três escolas de emergência no município de Urucará, oito no de Itapiranga, três no de Manicoré, nove no de São Paulo de Olivença, nove no de Urucurituba e uma no de Manacapuru.

3 - É publicado o Decreto n. ${ }^{\circ} 18$. de 3-4-44, do Estado de Goiás, que con cede subvenção de Cr\$ $10.000,00$ ao Educandário Santana, da cidade de Goiás.

3 - É publicado o Decreto n. ${ }^{\circ} 19$, de 3-4-44, do Estado de Goiás, que concede subvenção de $\mathrm{Cr} \$ 20.000,00$ à filial do Instituto Grambery, de Pires do Rio.

4 - É publicado o decreto do Estado do Amazonas, que aprova os concursos para preenchimento de cadeiras de $2 .^{\mathrm{a}} \mathrm{e}$ $3{ }^{\mathrm{a}}$ entrâncias nos municípios de Maués e Codajás.

4 - É publicado o Decreto nú mero 1.008, de 3-4-44, do Estado do Rio Grande do Sul, que concede ao Conselho Regional de Desportos um auxílio de Cr\$30.000,00.

5 - 'É publicado o decreto do Estado do Amazonas que cria, para o corrente ano letivo, duas escolas de emergência no município de Urucuri- 
tuba, sete no de Manicoré, seis no de Itapiranga, três no de Manacapuru. uma no de Canutama e uma no de Humaitá

5 - É publicado o ato . $^{\circ} 558$, de 4-444, do Estado de Pernambuco, que dá denominação de " Professor Alfredo Reis" a um dos grupos escolares em construção no interior do Estado.

8 - É publicada a resolução $\mathrm{n}^{\circ} 4$, de 29-3-44, da Secretaria Geral de Educação e Cultura da Prefeitura do Distrito Federal, que adota os programas de ensino primário organizados pelo Departamento de Educação Primária.

8 - É publicado o decreto do Estado do Amazonas, que cria, para o corrente ano letivo, três escolas de emergência no município de Manaus e sete no de Itacoatiara.

8 - É baixada a portaria $n . .^{\circ} 282$, do Departamento de Educação do Estado da Bahia, que recomenda aos professores e diretores de estabelecimentos de ensino a realização de festividades comemorativas ao " Dia Pan-Ameri-cano".

10 - É publicado o Decreto-lei número 985, de 8-4-44, do Estado de Santa Catarina, que declara de utilidade pública um terreno adquirido para ampliação do grupo escolar " José Ba-sílio", em Biguaçu.

11 - É publicado o Decreto número 7.758, de 10-4-44, da Prefeitura do Distrito Federal, que reorganiza, na Secretaria Geral de Educação e Cultura, o ensinopréprimário do Distrito Federal.

11 - É publicado o Decreto n. ${ }^{\circ} 8$, de 10-4-44, do Estado do Piaui, que regula a forma de concessão do ensino gratuito «o Colégio Estadual do Piau!
11 - É publicada a Portaria $n .^{\circ} 25$, da Diretoria do Serviço Estadual de Reeducação e Assistência Social no Rio Grande do Norte, que dá instruções para o funcionamento do Abrigo " Juiz Melo Matos", destinado ao recolhimento de menores abandonados do sexo masculino.

12 - É publicado o decreto do Estado do Amazonas, que cria, para o corrente ano letivo, seis escolas de emergência no município de Barreirinha e sete no de Itacoatiara.

12 - É publicado o Decreto-lei número 405, de 10-4-44, do Estado de Sergipe, que autoriza o aproveitamento dos professores da antiga Escola de Comércio Conselheiro Orlando, hoje Escola Técnica de Comércio de Sergipe e dá outras providências.

12 - É publicado o ato do governo do Estado do Rio de Janeiro que concede subvenção a escolas particulares de ensino primário do Estado.

13 - É publicada a ordem de serviço n." 1, de 3-4-44, do Departamento de Educação Nacionalista da Prefeitura do Distrito Federal, que dispõe sobre o " Plano Geral das Comemorações Cívicas" a ser observado, no corrente ano, nos estabelecimentos educacionais subordinados à Secretaria Geral de Educação e Cultura.

13 - São publicados os decretos do Estado do Amazonas, que mantêm no corrente ano letivo, sete escolas de emergência no município de Borda, 21 no de Manaus, sete no de Codajás, duas no de Parintins e uma em cada um dos seguintes municípios: Itacoatiara, Barreirinha, Manacapuru, Canutama, Maués, Eirunepé, Santa Maria da Boca do Acre e Uapés 
13 - É publicado o Decreto número 1.749 , de 12-4-44, do Estado do Rio de Janeiro, que extingue dois cargos de regente classe D do Quadro Permanente .

13 - É publicado o Decreto-lei número 985, de 12-4-44, do Estado de Santa Catarina, que declara de utilidade pública um terreno em Coqueiros, município de Florianópolis, para construção de um grupo escolar.

13 - É publicado o Decreto n. ${ }^{\circ} 11$, do Estado de Goiás, que cria a Escola "Presidente Vargas" no município de Goiás.

13 - É publicado o Decreto-lei n. ${ }^{\circ} 21$, do Estado de Goiás, que concede uma subvenção de Cr\$20.000,00 ao Ginásio Arquidiocesano do Planalto de Formosa.

14 - É publicada a ordem de serviço $n .^{\circ} 2$, de 4-4-44, do Departamento de Difusão Cultural da Prefeitura do Distrito Federal, que expede o regimento interno para os estabelecimentos de ensino supletivo (C.E.A. e C.T.A.), subordinados a esse Departamento.

14 - É publicado o decreto do Estado do Amazonas, que desdobra, no corrente ano letivo, as disciplinas da Escola Preparatória, anexa ao Instituto de Educação do Estado

14 - É publicado o Decreto n. ${ }^{\circ} 440$, de 13-4-44, do Estado da Paraíba, que concede licença para o funcionamento de uma "Escola de Professores", anexa ao Ginásio N. S. das Neves, em João Pessoa.

15 - É publicado o Decreto do Estado do Amazonas que dá subven ção a escolas particulares.

15 - O Departamento de Saúde Pública do Estado do Rio de Janeiro baixa instruções para o serviço de higiene escolar.
15 - É publicado o ato do governo $\mathrm{d}<>$ Estado do Rio de Janeiro, que dá permissão à escola de Cajueiros, no município de Macaé, para funcionar em 3 turnos, e à escola de Rodolfo Albino, no município de Cordeiro, para funcionar em regime de grupo escolar.

17 - É publicado o Decreto número 1.011, de 14-4-44, do Estado do Rio Grande do Sul, que dá ao grupo escolar " Protásio Alves", de Porto Alegre, a denominação de "Venezuela" .

17 - É publicado o Decreto número 1.012, de 15-4-44, do Estado do Rio Grande do Sul, que concede ao Colégio Municipal "Lemos Júnior", da cidade de Rio Grande, um auxílio de Cr\$30.000,00.

18 - É baixada a Portaria n. ${ }^{\circ} 523$, do Departamento de Educação do Es tado da Bahia, que recomenda aos pro fessores de todo o Estado a realização de festas comemorativas da data natalícia do Presidente Getúlio Vargas.

18 - É publicado o Decreto número 1.014, de. 18-4-44, do Estado do Rio Grande do Sul, que dá a denominação de " Professor Chaves", ao grupo es colar de Livramento, criado pelo Decreto n. ${ }^{\circ} 977$, de 20-1-44.

18 -É publicado o Decreto número 1.015, de 18-4-44. do Estado do Rio Grande do Sul, que dá a denominação de " Moisés Viana" ao grupo escolar de Vila Flórida, no município de San tiago.

19 - É publicado o Decreto do Estado do Amazonas, que cria, para ocorrente ano letivo, 22 escolas de emergência no município de Manaus, quatro no de Itacoatiara. uma no de Uapés, duas no de Urucutituba, três no de Urucará, uma no de Parintins, uma no de Manicoré, seis no de Mana- 
capuru, duas no de Fonte Boa, uma no de São Paulo de Olivença, seis no de Benjamin Constant, oito no de Canutama e duas no de Carauári.

19 - Por Decreto n. ${ }^{\circ} 1.257$, do Estado do Rio Grande dó Norte, são criadas 192 escolas isoladas, no interior do Estado.

19 - É publicado o Decreto número 2.928, de 17-4-44, do Estado de Ala goas, que cria três cargos de monitor de educação fisica.

19 - É publicado o Decreto número 2.929, de 19-4-44, do Estado de Ala goas, que estabelece a gratuidade de ensino de qualquer grau, nos estabelecimentos de ensino do Estado.

19 --- É publicado o ato n. ${ }^{\circ} 4$, de 12-444, da Secretaria de Educação e Saúde Pública do Estado de São Paulo, que dispõe sobre a remoção de professores de $3 .^{\circ}$ estágio, no interesse do ensino.

19 - São publicadas as instruções do Departamento de Educação do Estado de São Paulo, para a escolha de livros didáticos no corrente ano, bem como a relação dos livros autorizados, com preços de venda ao público

$20^{\prime}$ - É publicado o Decreto n. ${ }^{\circ} 441$, de 19-4-44, do Estado da Paraíba, que cria 50 escolas primárias a serem localizadas no interior do Estado.

20 - É publicado o Decreto n." 442, de 19-4-44, do Estado da Paraíba, que cria 10 escolas primárias noturnas, a serem localizadas no interior do Estado.

. 20 - É publicado o Decreto número 1.130, de 19-4-44, do Estado do Rio de Janeiro, que, cria a Escola de Enfermagem do Estado do Rio de Janeiro (E.E.E.R.J.).
21 - Pela Portaria n. ${ }^{\circ} 13$, o Diretor do Departamento de Educação do Estado, de São Paulo incumbe à Assistência Técnica do Ensino. Primário a tarefa de atualizar os programas do ensino em. uso nas escolas primárias do Estado.

22 - É publicado o Decreto número 7.768, de 20-4-44, da Prefeitura do Distrito Federal, que baixa o Regulamento do ensino primário do Distrito Federal.

25 - É publicado o Decreto-lei número 1.214, do Estado do Amazonas, que restaura a segunda cadeira de português $\mathrm{c}$ noções de literatura do Instituto de Educação do Amazonas.

25 - O governo do Estado de Santa Catarina concede duas bolsas escolares de Cr\$ 400,00 mensais a estudantes de engenharia.

25 - É publicado o Decreto n. ${ }^{\circ} 12$, do Estado de Goiás, que cria uma escola isolada, anexa ao Preventório " Afrânio de Azevedo, com sede em Goiânia.

26 - É publicado o Decreto número 1.016, de 25-4-44, do Estado do Rio Grande do Sul, que eleva à categoria de grupo escolar as escolas reunidas de Vila Jardim, município de Porto Alegre.

26 - É publicado o Decreto número 1.017, de 25-4-44, do Estado do Rio Grande do Sul, que concede à Superin tendência do Ensino Profissional da Secretaria de Educação e Cultura um crédito especial de Cr\$50.000,00.

26 - É publicado o Decreto número 1.018, de 25-4-44, do Estado do Rio Grande do Sul, que concede ao grupo escolar de Beluno, em São Francisco de Assis, um auxílio de Cr\$ 1200,00 . 
27 - É publicado o Decreto-lei número 779, de 18-4-44, do Estado do Piaui, que cria o Departamento Estadual da Criança.

27 - É publicado o Decreto-lei número 1.141, de 26-4-44, do Estado do Ceará, que dispõe sobre a fiscalização das escolas normais do Estado.

27 - É publicada a resolução número 449, de 26-4-44, do Estado do Espírito Santo, que aprova os programas para os Cursos de Formação de Professores.

27 - É publicado o Decreto-lei nú mero 1.134, de 26-4-44, do Estado do Rio de Janeiro, que cria 15 cargos provisórios da classe $\mathrm{A}$, no quadro do ensino primário.

28 - Pela portaria n. ${ }^{\circ}$ 14, o Diretor do Departamento de Educação do Es tado do Rio de Janeiro recomenda aos diretores de estabelecimentos oficiais de ensino a rigorosa observância dos textos contidos no art. 133, da Constituição, de 10-11-37. e das instruções publicadas no Diário Oficial de 4-7-43.

28 --- É publicado o Decreto número 1.135, de 27-4-44, do Estado do Rio de Janeiro, que extingue um cargo da classe $\mathrm{D}$, da carreira de professor de ensino industrial e cria outro, na mesma carreira, de música e canto orfeônico.

28 - É publicado o Decreto número 1.024; de 27-4-44, do Estado do Rio Grande do Sul, que concede ao grupo escolar " Matias de Albuquerque", em Aberta dos Morros, um auxílio de Cr? 1000,00 .

29 - É publicado o Decreto-lei número 781, de 28-4-44, do Estado do Piauí, que concede a subvenção anual de $\mathrm{Cr} \$$ 6.000,00 ao externato "Rui Barbosa", da capital.
29 - É publicado o Decreto n. ${ }^{\circ} 14$, do Estado de Goiás, que cria uma escola isolada, mista, na Fazenda "Olho d'Água", município de Corumbá.

30 - É publicado o Decreto-lei número 5.498, de 29-4-44, do Estado do Espírito Santo, que regula o pagamento de aulas suplementares aos professores do Colégio Estadual da Escola Normal " Pedro II" e do Liceu " Muniz Freire".

$$
\begin{gathered}
\text { III - ATOS DA ADMINISTRAÇÃo } \\
\text { MUNICIPAL }
\end{gathered}
$$

13 - É publicado o Decreto-lei número 33, da Prefeitura Municipal de Piracuruca (Piauí), que regula a concessão de auxílios a instituições de assistência social ou cultural.

19 - A Prefeitura Municipal de Bandeirantes (Paraná) inaugura duas escolas de ensino primário

24 - É publicado o Decreto-lei número 16, de 23-3-44, da Prefeitura municipal de Ipiranga (Paraná), que ratifica o Convênio Estadual de Ensino Primário.

28 - A Prefeitura Municipal de Sobradinho (Rio Grande do Sul) apresenta ao Conselho Administrativo do Estado um projeto de decreto-lei que institui um curso de férias, ministrado por professores do grupo escolar estadual daquela cidade, para professores municipais.

$$
\text { IV — NOTICIÁRIO }
$$

1 - É designado para exercer interinamente as funções de Secretário de Educação e Cultura do Estado do Rio Grande do Sul, o Dr. Caio Brandão de Melo. 
2 - Assume interinamente o cargo de Diretora do Departamento de Educação Primária c Normal, da Secretaria e Cultura do Estado do Rio Grande do Sul, a professora Sílvia Melo.

2 - É fundada, em João Pessoa (Paraíba), a "Sociedade de Cultura do Estudante Paraibano", anexa ao -Colégio Estadual da Paraíba.

5 - É nomeado para exercer o cargo de Secretário de Educação e Saúde do Estado da Bahia, o Dr, Manuel Artur Vilaboim.

5 - Noticia-se que a Sociedade "Jacinto Godói", de Erechim (Rio Grande do Sul) iniciou um movimento de amparo aos menores abandonados.

5 - Noticia-se que o Secretário de Educação e Cultura do Estado do Rio Grande do Sul encaminhou ao Inter ventor Federal um projeto de decretolei que concede autonomia à Universi dade de Porto Alegre.

6 - Inaugura-se a distribuição da "sopa escolar" no grupo escolar de Pindorama (São Paulo).

$6-\dot{E}$ doada, pela Legião Brasileira de Assistência, a importância de Cr\$. $1.000,00$ ao grupo escolar de Matão (São Paulo).

6 - É criado em Guariba (São Paulo) o serviço de "merenda escolar".

6 - Noticia-se a instalação, em Óleo (São Paulo) da cooperativa escolar "Visconde de Mauá".

6 - É doada, pela Legião Brasileira de Assistência, a importância de Cr\$600,00 à caixa escolar do grupo escolar de Itajobi (São Paulo).

6 - Noticia-se a inauguração do "copo de leite" nos grupos escolares de Cajobi e de Valinhos (São Paulo).
6 - É lançada a pedra fundamental do grupo escolar de Tapuias, em Itápolis (São Paulo).

6 - Noticia-se a inauguração do pavilhão " Anita Costa" destinado à sopa escolar do grupo escolar " Rafael de Moura Campos", em Botucatu (São Paulo).

6 - Visita a cidade de Porto Alegre (Rio Grande do Sul), o Presidente do Conselho Nacional do Ensino Primário e Normal do Uruguai.

7 - Noticia-se que as caixas escolares dos estabelecimentos de ensino da Paraíba vão iniciar a distribuição de uniformes para os alunos pobres.

9 - O Ministro da Educação encarrega o Diretor do Instituto Nacional de Estudos Pedagógicos da organização do projeto de programa da II. ${ }^{a}$ Conferência Nacional de Educação, a realizar-se em fins do corrente ano

9 - Noticia-se que foi criado na Estrada de Ferro Central do Brasil um curso de instrução elementar, que funcionará junto a todas as oficinas e núcleos ferroviários.

10 - O Liceu " Manuel Viana", de Paranaguá (Paraná), cria a "Bolsa do Estudante", destinada aos menores pobres, de 12 a 18 anos.

10 - Realiza-se em Porto Alegre (Rio Grande do Sul) uma reunião preparatória para a fundação da Delegacia do Sindicato dos Estabelecimentos de Ensino Secundário e Primário, do Rio de Janeiro.

12 - Instala-se a 13.* Missão Ruralista Escolar, em Escada (Pernambuco) .

12 - Noticia-se que a Faculdade de Direito de Recife (Pernambuco) 
REVISTA BRASILEIRA DE ESTUDOS PEDAGÓGICOS

presta homenagem à memória do jurista brasileiro Ministro Rodrigo Otávio.

14 - É comemorado nas escolas de todo o país o "Dia Pan-Americano".

14 - Toma posse no cargo de Secretário da Educação da Bahia o Sr. Manuel Artur Vilaboim.

15 - É instalado o Internato da Casa de Menores "Juvino Barreto", da cidade de Mossoró (Rio Grande do Norte).

15 - É transferido o curso noturno oficial de "Portugal Pequeno", para Ponta da Areia, em Niterói (Rio de Janeiro) .

17 - É lavrada, em Farroupilha (Rio Grande do Sul), a escritura de requisição do terreno destinado à instalação da " Colônia de Estudos e Férias".

18 - É doada ao Circulo Operário, por particulares a importância de .... Cr\$ $10.000,00$ para os serviços de assistência à infância tuberculosa ou pré-tuberculosa de Porto Alegre (Rio Grande do Sul).

19 - Realiza-se, em praça fronteira ao edifício do Ministério da Educação, no Distrito Federal, o lançamento da pedra fundamental do Monumento à Juventude.

19 - Em todas as escolas do país é festivamente comemorado o aniversário do Presidente Getúlio Vargas.

19 - Noticia-se a instalação do curso da escola normal rural de Manacapuru (Amazonas).

19 - É instalado, em Terezina (Piauí), o Departamento Estadual da Criança.

19 - Em Teresina (Piauí), inaugura-se um jardim de infância fundado pila Legião Brasileira de Assistência.
19 - É fundado o Teatro Infantil " Abelardo Jurema", anexo ao grupo escolar "Rio Branco", da cidade de Patos (Paraíba).

19 - Noticia-se a inauguração de quatro grêmios literários em grupos escolares e colégios de Recife (Pernambuco) e mais quatro em grupos escolares do interior do Estado.

19 - Inauguram-se dois museus e cinco bibliotecas infantis em grupos escolares do interior do Estado de Pernambuco.

19 - Noticia-se a realização, em Recife (Pernambuco), de um concurso escolar intitulado " Páginas Infantis", patrocinado pelo Departamento de Educação do Estado.

19 - É lançada a pedra fundamental de uma creche a ser construída em Recife (Pernambuco), pela Legião Brasileira de Assistência.

19 •- Noticia-se a inauguração do grupo escolar " Clara Camarão" em Recife (Pernambuco).

19 - Noticia-se a fundação de oito jornais escolares em grupos escolares e colégios da capital e do interior do Estado de Pernambuco, pela Legião Brasileira de Assistência.

19 - Noticia-se a inauguração do grupo escolar " Clara Camarão" cm Recife (Pernambuco).

19 - Noticia-se a fundação de oito jornais escolares em grupos escolares e colégios da capital e do interior do Estado de Pernambuco.

19 - Noticia-se a instalação de nove clubes agrícolas $\mathrm{cm}$ grupos escolares do interior do Estado de Pernambuco e de um na escola "Aires Gama", da capital do Estado. 
19 - É inaugurado, na cidade de Paranaguá (Paraná) o grupo escolar "Estados Unidos da América".

19 - É inaugurado o novo prédio do grupo escolar " Visconde de Guarapuava" na cidade de Guarapuava (Paraná) .

19 - É inaugurada a Escola de Trabalhadores Rurais da cidade de Santo Antônio da Platina (Paraná).

19 - São fundados clubes agrícolas nos grupos escolares "Hugo Simas" e " Ministro Osvaldo Aranha" da cidade de Londrina (Paraná).

19 - É criado, na Colônia Esperança, município de Caviúva (Paraná), um grupo escolar que tomará o nome de "19 de Abril".

19 - É lançada a pedra fundamental do grupo escolar do bairro da Colônia Dantas, em Curitiba (Pa-raná) .

19 - Inaugura-se em Porto Alegre (Rio Grande do Sul) o Hospital de Pronto Socorro, que terá um Departamento Cultural, com cursos de aperfeiçoamento para médicos e enfermeiros.

19 - Inauguram-se, no Rio Grande do Sul, seis edifícios escolares, em comemoração do aniversário do Presidente Getúlio Vargas.

20 - Noticia-se que o Sindicato dos Oficiais Marceneiros manterá em 1944, como nos anos anteriores, aulas gratuitas de desenho técnico profissional.

20 - Noticia-se que em Urussuí (Piauí) foi instalada uma escola primária municipal. •

20 - Foi inaugurada em Campo Maior (Piauí) a escola primária Santo Antônio.
21 - Noticia-se a construção no Estado de São Paulo de quatro prédios escolares, por iniciativa particular, em Catanduva, Taquaritinga, Fernando Prestes e Pindorama.

22 - O Diretor do Departamento Nacional do S.E.N.A.I. informa que matriculará, no corrente ano, 20.000 alunos em suas escolas.

22 - Noticia-se que foi inaugurado o novo prédio da Escola Normal " João Neves da Fontoura", em Cachoeira (Rio Grande do Sul).

22 - Noticia-se a instalação da Creche N. S. Medianeira em São Leo poldo (Rio Grande do Sul).

23 - Noticia-se que a Legião Brasi leira de Assistência concedeu à Asso ciação Cooperadora da Escola, em Porto Alegre (Rio Grande do Sul), auxílio para a distribuição de sopa a mais de dez mil alunos dos grupos escolares da capital

23 - Inicia-se, em Porto Alegre (Rio Grande do Sul), o programa comemorativo do centenário do nascimento do professor Apolinário Porto Alegre.

28 - Noticia-se que foi inaugurado o grupo escolar " General Soares Andréa", em Barra do Chuí (Rio Grande do Sul)

29 - Noticia-se que 38 prefeituras municipais do Estado do Rio Grande do Norte já ratificaram o Convênio Estadual de Ensino Primário, de que trata o Decreto-lei federal n. ${ }^{\circ} 4.958$, de 14-11942.

30 - Noticia-se que o Departamento de Educação do Estado do Ceará enviou ao Presidente da Cruzada Nacional de 
Educação a importância de Cr\$ $5.000,00$ arrecadados nas escolas do Estado e que se destinam ao Fundo Nacional de Ensino Primário.

30 - Realiza-se, no Palácio do Comércio, de Fortaleza (Ceará), uma conferência do Dr. Urbano de Almeida, Delegado Reginal do S.E.N.
A.I., sobre as finalidades do ensinei industrial.

30 - Noticia-se que o Departamento de Educação do Estado da Bahia está fazendo distribuir 20.000 livros, 50.000 lápis e 8.000 folhas de cartolina entre escolares da capital $\mathrm{c}$ do interior do Estado.

\section{INFORMAÇÃO DOS ESTADOS}

\section{ALAGOAS}

O Diretor do Departamento de Educação do Estado, Padre Medeiros Neto, fêz as seguintes declarações ao " Jornal de Alagoas", de Maceió:

"E' Alagoas, porventura, um Estado onde o ensino primário se encontre desvitalizado? Não. Um Estado que possui 33 municípios e detém 43 grupos-escolares com prédios próprios, se encontra em situação, relativamente privilegiada. Ademais, este número, ainda este ano, será acrescido de dois outros grupos, construídos, técnica e pedagògi-camente. Como noutras unidades da Federação, os nossos grupos tendem a dispor de Biblioteca Infantil, Museu Escolar e de melhor aparelhamento di-dático-escolar. As atividades e instituições auxiliares do ensino já existem: clubes de leitura, cooperativas, caixas escolares, excursões.

Em 19-11, no Instituto Nacional de Estudos Pedagógicos, Alagoas foi o Estado mais bem representado no Curso de Férias que ali se fazia, em combinação com a Associação Brasileira de Educação. Estagiaram, ali, por durante 2 meses, 3 professores primários do Estado. Com estes elementos e com a dedicação do professorado, em geral, se pode fazer e marcar uma época de mais atividade na vida educacional dos grupos escolares.
Foi instalada, na Diretoria da Educação, uma Seção de Pesquisas Pedagógicas. Por intermédio desta seção, pude regularizar o seguinte: divisão do programa em etapas letivas, provas de aplicação (mensalmente), provas seletivas (trimestralmente) e absoluta vigilância no aproveitamento dos alunos. A prova clássica, formalística, cedeu lugar às provas com aplicação de testes escolares e questões objetivas. Destarte, o rendimento escolar deixará de ser aparente para tornar-se real. A promoção será uma questão de mérito. E passará o nosso ensino primário de ônus para compensação moral ao Estado. Ademais. com este processo, se farão as classes selecionadas, que oferecerão oportunidade para a criação dos quadros nivelados, dentro do espírito da renovação educacional".

\section{BAHIA}

Pelo Decreto-lei n. ${ }^{\circ} 15$, de 6 de setembro de 1943, estabeleceu o governo do Estado da Bahia um plano quatrie-nal para a construção e instalação de escolas públicas.

A parte da construção de novos prédios escolares e terminação das construções, que se acham em andamento, coube à Secretaria de Viação e Obras Públicas. Quanto ao que toca à insta- 